\title{
Measurement of radiographic changes occurring in rheumatoid arthritis by image analysis techniques
}

\author{
P A GAYDECKI, ${ }^{3}$ M BROWNE, ${ }^{3}$ H MAMTORA ${ }^{2}$ AND D M GRENNAN ${ }^{1}$
}

From the ${ }^{1}$ University of Manchester Rheumatic Diseases Centre, Hope Hospital, Salford; the ${ }^{2}$ Department of Radiology, Hope Hospital; and the ${ }^{3}$ Department of Instrumentation and Analytical Science, UMIST

SUMMARY We have applied image analysis techniques to serial measurements of bone contour ii standard radiographs of single small joints of the hands in subjects with rheumatoid arthriti (RA) and controls. Adequate reproducibility was shown in 20 controls radiographed twice over $\vec{A}$ six month period. The technique showed significant changes in a proximal interphalangeal join $\$$ of 13 of 15 patients with RA studied over periods of three to 10 months. In further serial studieg in selected small joints of RA hands significant changes could be shown as early as four monthsThese results justify further development of these techniques to allow their full scale evaluatio in multiple joints in patients with RA receiving long term drug therapy.

Changes in periarticular bone are a major feature of both rheumatoid arthritis (RA) and osteoarthritis. In RA the ability of drug therapy to prevent periarticular bone destruction in severe disease is an important measure of drug efficacy. Standard methods of scoring radiological change in joints are subjective, insensitive, and difficult to measure. They are mainly based on either comparisons of radiographs with those in a standard atlas or on counting erosions in particular joints. ${ }^{12}$ Potentially measurable features of bone changes in arthritis include changes in periarticular bone density and changes in bone contour such as the bone loss or erosions in RA or osteophytosis in osteoarthritis. Techniques which have been used elsewhere to provide sensitive, in vitro measurements of bone density include photon absorptiometry and local neutron activation analysis. ${ }^{34}$ Both are limited in application to serial measurements in an individual since difficulty in accurate repositioning and neutron activation analysis requires the use of sophisticated equipment which is not universally available. A microfocal radiographic technique has been used to examine the fine details of bone changes occurring in arthritis ${ }^{56}$ but has the disadvantage that a relatively small field is examined in each film. We have developed image analysis techniques to measure the serial changes in bone contour occur-

Accepted for publication 18 September 1986.

Correspondence to Dr D M Grennan, Rheumatic Diseases Centre, Hope Hospital, Salford M6 8HD. ring in RA, and in the present study have investio gated the feasibility of applying these techniques to the investigation of radiographs taken with standar $\bar{\phi}$ radiographic apparatus available to routine hospita $x$ ray departments. We have examined both the reproducibility of the measurements in non- $R$ hands and their sensitivity in detecting changes in selected small joints of the hands of patients wite RA followed up for periods of up to two years?

\section{Patients and methods}

IMAGE ANALYSIS AND RADIOGRAPHIC TECHNIQUE

Radiographs were taken with the hands immersed in $5 \mathrm{~cm}$ of water to minimise soft tissue effects (in parallel study we are analysing changes in periarticut lar bone density) and using a jig which ensureet. constant hand position for repeated examinations $N$ Agfa Mamoray RP3 film was used and exposed at $4 R$ kVP, $100 \mathrm{~mA}$ at six seconds. Films were develope by a conventional automatic film processing machine.

The analysis of radiographs was performed with $\Psi$ Magiscan 2 image processor which digitised at vide 8 frame rate a signal from a standard TV camera. $A^{+}$ spatial resolution of $512 \times 512$ pixels and 6 bit grep level resolution (64 levels) was available. With the aid of a light pen the operator indicated the bon? chosen for examination by placing control points to define the area of interest along the edge of the image appearing on the screen. The software refined 
these points and used them to segment the entire bone by fitting a Catmull-Rom spline along the perimeter. ${ }^{78}$ (A Catmull-Rom spline is a particular type of contouring technique which uses low order polynomial sections or splines to interpolate the boundary contour between control points.) The orientation of the bone in relation to the camera was not critical $\left( \pm 60^{\circ}\right)$ since registration coding automatically aligned the image with previous bone images in a given series. After identification of the bone centroid (the centre of gravity of a plane sheet of the same shape as the bone) the 'polar signature' (Fig. 1) of a $120^{\circ}$ arc of the bone perimeter which includes the periarticular bone contour was defined. Each polar signature consists of 240 individual points (see Fig. 1). Polar signatures of the same joint in successive radiographs could then be compared by correlation coefficients(r), perimeter ratio (that is ratio of perimeter of polar signature baseline/ perimeter of polar signature on follow up), similar ratio of areas of polar signatures, ratio of area/ square of perimeter, and calculation of mean and standard deviation (SD) of the mean after subtraction. Examples of polar signatures from pairs of radiographs which show no change and significant changes respectively are shown in Figs 2 and 3. From consideration of serial radiographs of control hands the $95 \%$ confidence limits for serial measurements were calculated, and changes in RA films subsequently analysed were considered as significant if they fell outside these limits.

\section{S U B J E C T S}

Initial reproducibility studies were performed in 20 control subjects who had baseline and repeat radiographs at intervals of six months. These subjects were chosen from a rheumatology outpatient clinic and included patients with soft tissue rheumatic disorders, cervical and lumbar spondylosis, and excluded patients with clinical evidence of inflammatory joint disease. All subjects gave informed consent to taking part in the study. Their ages ranged from 24 to 65 years. Changes occurring in the proximal interphalangeal joints (PIP) of the middle finger in these subjects were used to calculate $95 \%$ confidence limits.

Radiographs of 28 patients with RA were analysed. Fifteen sets of films from seven patients were used to compare image analysis and standard Larsen
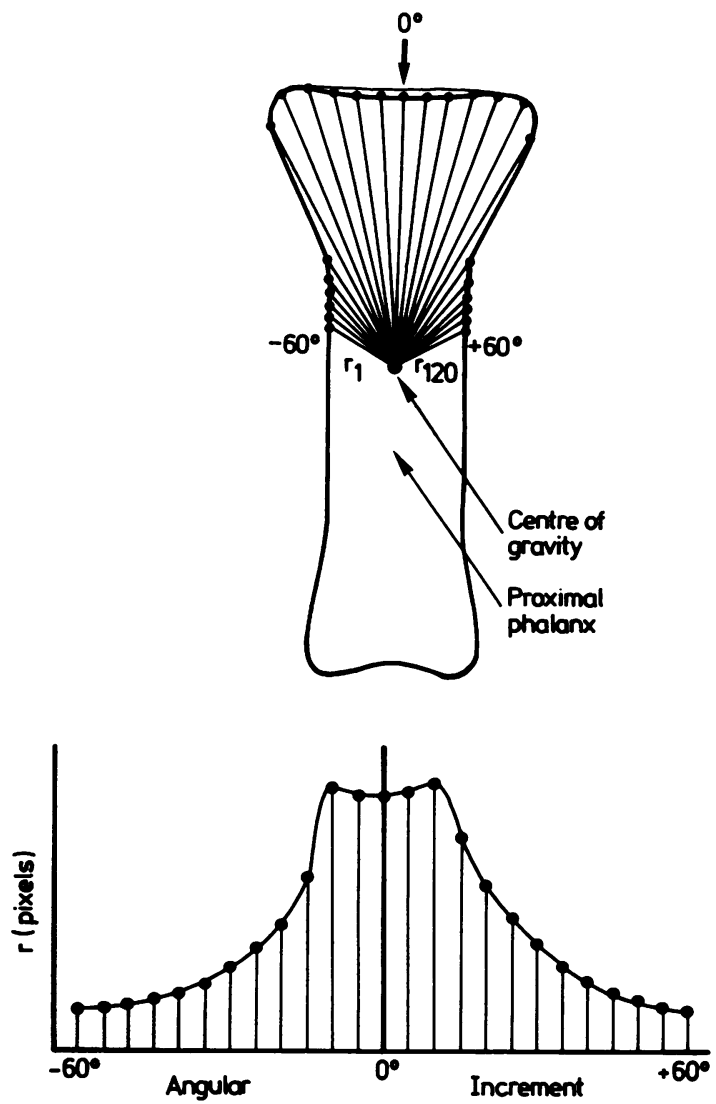

Fig. 1 Principle of the polar signature measurement. For purposes of clarity the polar signature is shown with $5^{\circ}$ increments. In practice it is 10 times this, i.e., $0 \cdot 5^{\circ}$ increments, comprising 240 readings.

Table 1 Reproducibility measurements derived from $20 \times 2$ control films, using the proximal phalanx of the middle finger (six month interval)

\begin{tabular}{|c|c|c|c|c|c|c|}
\hline Parameter & $\begin{array}{l}\text { Perimeter }(P) \\
\text { ratio }\end{array}$ & $\begin{array}{l}\text { Area }(A) \\
\text { ratio }\end{array}$ & $\begin{array}{l}A / P^{2} \\
\text { ratio }\end{array}$ & $\begin{array}{l}\text { Polar signature } \\
\text { subtraction } \\
\text { (mean) }\end{array}$ & $\begin{array}{l}\text { Polar signature } \\
\text { subtraction (SD) }\end{array}$ & $r$ \\
\hline $\begin{array}{l}\text { Mean } \\
\text { SD } \\
\text { Reproducibility (\%) } \\
95 \% \text { Confidence } \\
\quad \text { limits }\end{array}$ & $\begin{array}{l}0.9996 \\
0.0097 \\
0.9704 \\
0.9806 \\
\text { to } \\
1.0186\end{array}$ & $\begin{array}{l}0.9967 \\
0.0154 \\
1.5451 \\
0.9665 \\
\text { to } \\
1.0269\end{array}$ & $\begin{array}{l}0.9976 \\
0.0166 \\
1.6640 \\
0.9965 \\
\text { to } \\
1.0301\end{array}$ & $\begin{array}{l}0 \cdot 2091 \\
0 \cdot 7016 \\
- \\
-1 \cdot 174 \\
\text { to } \\
1 \cdot 5842\end{array}$ & $\begin{array}{l}2 \cdot 0076 \\
0.5059 \\
-\end{array}$ & $\begin{array}{l}0.9984 \\
0 \cdot 0007 \\
0.0694\end{array}$ \\
\hline
\end{tabular}




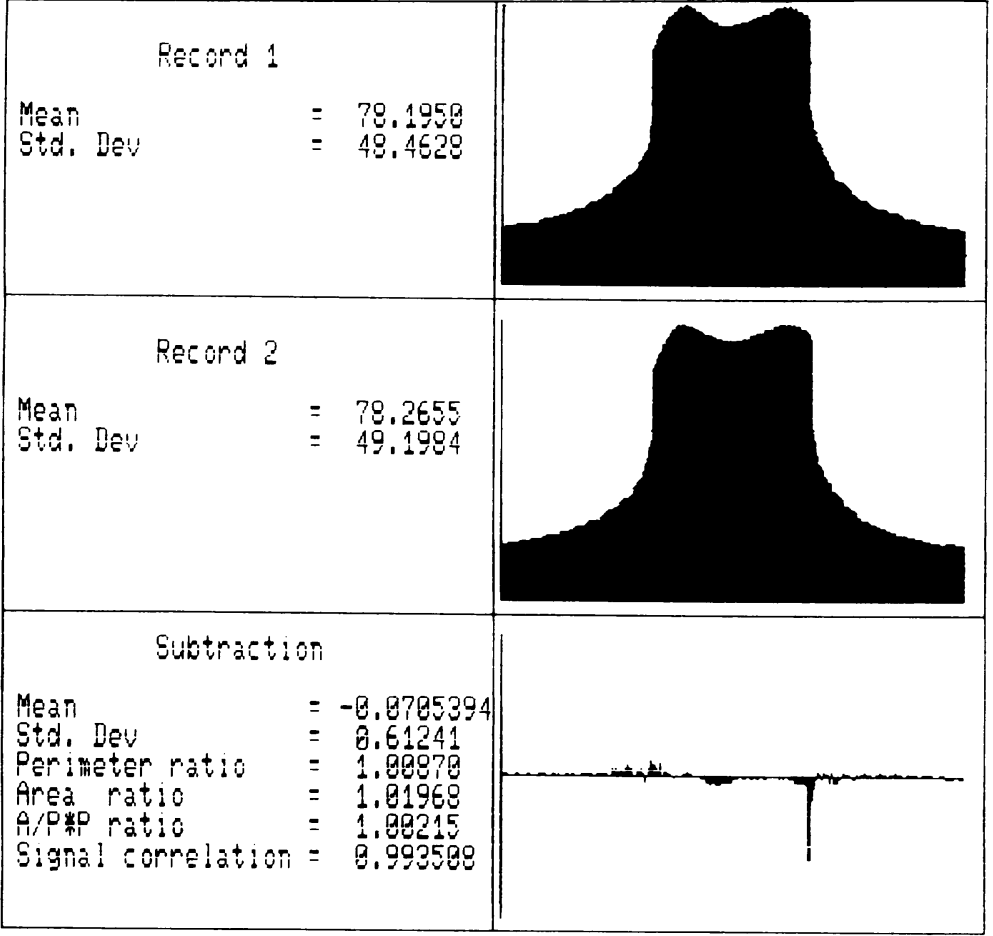

Fig. 2 Image subtraction of control radiographs (proxim interphalangeal (PIP) joint) showing no significant serial change of polar signatures defining periarticular surface of head of proximal phalanx. ( $P^{*} P=$ square of perimeter $)$.

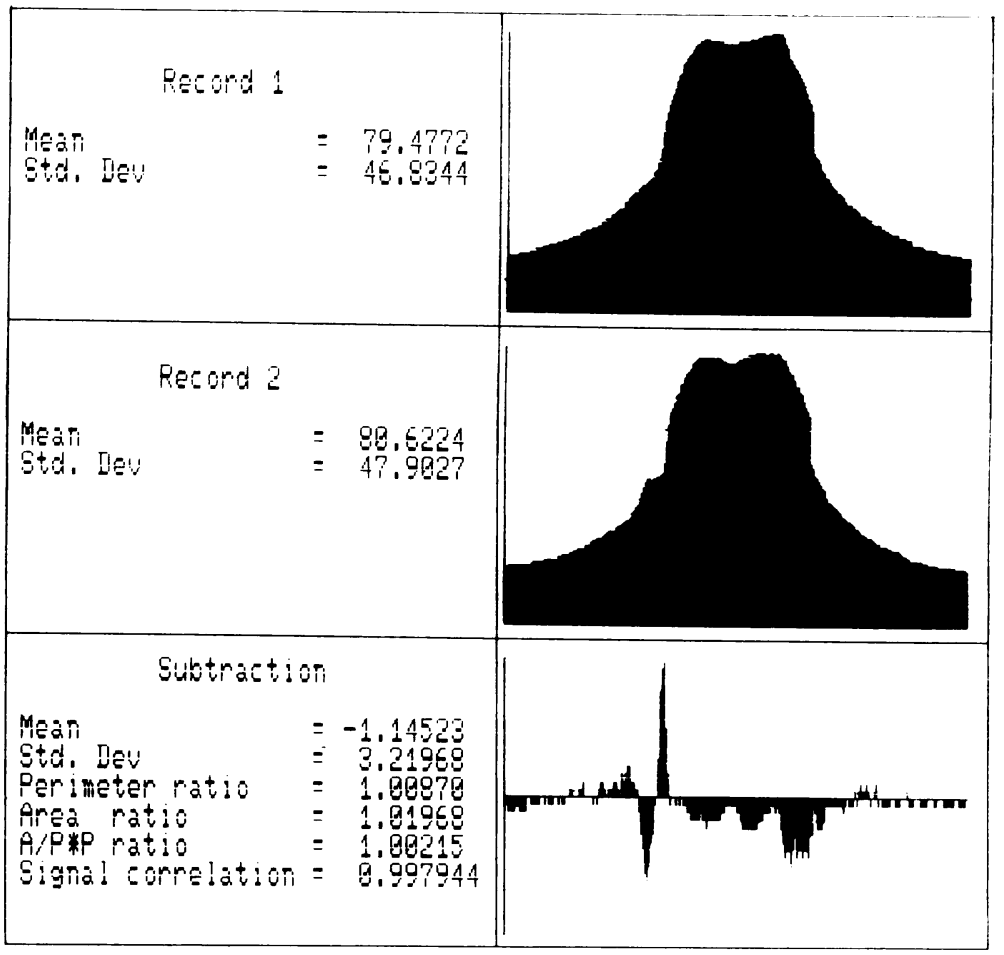

Fig. 3 Image subtraction of RS radiographs ( $P I P$ joints) showing significant serial chang? of polar signatures. 
visual scoring of radiological changes occurring in the middle finger PIP joint.

The visual grading was decided by consensus between two observers (DMG, HM), and the change in grading subsequently calculated. In the 21 further RA patients (Tables 3 and 4) we have investigated the time taken for radiographic changes to develop in PIP and metacarpophalangeal (MCP)

Table 2 Comparison of image analysis and Larsen index measures of radiological changes in head of proximal phalanx of middle finger ( $R A$ hands)

\begin{tabular}{|c|c|c|c|c|c|}
\hline Sex & Age (years) & $\begin{array}{l}\text { Time from } \\
\text { baseline (months) }\end{array}$ & $S D$ & Significance & $\begin{array}{l}\text { Change in } \\
\text { Larsen score }\end{array}$ \\
\hline $\mathbf{F}$ & 37 & 3 & 3.0655 & 0.05 & 0 \\
\hline $\mathbf{F}$ & 41 & 6 & 3.4577 & $0 \cdot 01$ & 2 \\
\hline $\mathbf{F}$ & 41 & 6 & $3 \cdot 0780$ & 0.05 & 2 \\
\hline $\mathbf{M}$ & 53 & 5 & $5 \cdot 8083$ & 0.001 & 1 \\
\hline $\mathbf{M}$ & 53 & 6 & $4 \cdot 4162$ & $0 \cdot 001$ & 1 \\
\hline $\mathbf{M}$ & 59 & 4 & $2 \cdot 4581$ & NS & 0 \\
\hline $\mathbf{M}$ & 59 & 8 & $5 \cdot 2230$ & 0.001 & 2 \\
\hline $\mathbf{M}$ & 59 & 4 & 3.7874 & 0.001 & 0 \\
\hline $\mathbf{M}$ & 59 & 8 & $4 \cdot 1609$ & 0.001 & 0 \\
\hline $\mathbf{M}$ & 60 & 5 & 5.9135 & 0.001 & 0 \\
\hline $\mathbf{M}$ & 60 & 10 & 8.0915 & 0.001 & 1 \\
\hline $\mathbf{M}$ & 68 & 7 & $5 \cdot 8631$ & 0.001 & 1 \\
\hline $\mathbf{M}$ & 68 & 10 & $5 \cdot 7937$ & 0.001 & 1 \\
\hline
\end{tabular}

$\mathrm{SD}=$ standard deviation of polar signature subtraction values.

Significance $=$ statistical significance of change in polar signature.

Table 3 Erosive changes in periarticular bone outlines, estimated by the standard deviation and correlation coefficient of subtracted polar signatures (female patients)

\begin{tabular}{|c|c|c|c|c|c|}
\hline Patient No & Age (years) & $\begin{array}{l}\text { Time from } \\
\text { baseline (months) }\end{array}$ & Subtraction $S D$ & $r$ & Significance (of $S D$ ) \\
\hline \multirow[t]{3}{*}{1} & 15 & 5 & 1.7573 & 0.9979 & NS \\
\hline & & 11 & $1 \cdot 8104$ & 0.9979 & NS \\
\hline & & 17 & $2 \cdot 0171$ & 0.9973 & NS \\
\hline \multirow[t]{2}{*}{2} & 24 & 1 & 1.4602 & 0.9996 & NS \\
\hline & & 9 & $2 \cdot 4593$ & 0.9991 & NS \\
\hline \multirow[t]{2}{*}{3} & 37 & 4 & $2 \cdot 0471$ & 0.9991 & NS \\
\hline & & 15 & $4 \cdot 8055$ & 0.9946 & $<0.001$ \\
\hline \multirow[t]{2}{*}{4} & 38 & 4 & 2.9588 & 0.9981 & $<0 \cdot 1$ \\
\hline & & 7 & 3.0060 & 0.9981 & $<0.05$ \\
\hline \multirow[t]{3}{*}{5} & 41 & 9 & $3 \cdot 2276$ & 0.9981 & $<0.02$ \\
\hline & & 18 & $3 \cdot 8493$ & 0.9978 & $<0.001$ \\
\hline & & 23 & 4.4196 & 0.9970 & $<0.001$ \\
\hline \multirow[t]{3}{*}{6} & 45 & 4 & $3 \cdot 1228$ & 0.9968 & $<0.05$ \\
\hline & & 6 & $3 \cdot 2287$ & 0.9966 & $<0.02$ \\
\hline & & 12 & $2 \cdot 9938$ & 0.9971 & NS \\
\hline \multirow[t]{5}{*}{7} & 47 & 2 & 1.9623 & 0.9976 & NS \\
\hline & & 4 & $2 \cdot 0238$ & 0.9974 & NS \\
\hline & & 7 & $2 \cdot 3698$ & 0.9965 & NS \\
\hline & & 15 & $2 \cdot 2611$ & 0.9968 & NS \\
\hline & & 25 & $2 \cdot 2749$ & 0.9968 & NS \\
\hline \multirow[t]{3}{*}{8} & 51 & 6 & $2 \cdot 2332$ & 0.9975 & NS \\
\hline & & 11 & $2 \cdot 1320$ & 0.9977 & NS \\
\hline & & 18 & $2 \cdot 0118$ & 0.9980 & NS \\
\hline \multirow[t]{3}{*}{9} & 62 & 8 & 1.9948 & 0.9985 & NS \\
\hline & & 11 & $2 \cdot 5901$ & 0.9974 & NS \\
\hline & & 18 & $2 \cdot 8632$ & 0.9968 & NS \\
\hline \multirow[t]{2}{*}{10} & 66 & 2 & $3 \cdot 6272$ & 0.9943 & $<0.002$ \\
\hline & & 14 & $4 \cdot 4708$ & 0.9907 & $<0.001$ \\
\hline \multirow{2}{*}{11} & 72 & 4 & 3.6271 & 0.9932 & $<0.002$ \\
\hline & & 6 & $6 \cdot 0080$ & 0.9814 & $<0.001$ \\
\hline
\end{tabular}


Table 4 Erosive changes in periarticular bone outlines, estimated by the standard deviation and correlation coefficient ơ subtracted polar signatures (male patients)

\begin{tabular}{|c|c|c|c|c|c|}
\hline Patient No & Age (years) & $\begin{array}{l}\text { Time from } \\
\text { baseline (months) }\end{array}$ & Subtraction SD & $r$ & Significance (of SD) \\
\hline \multirow{2}{*}{1} & & 9 & $2 \cdot 8950$ & 0.9984 & $<0 \cdot 1$ \\
\hline & & 17 & $3 \cdot 0144$ & 0.9981 & $<0.05$ \\
\hline \multirow[t]{3}{*}{2} & 49 & 2 & 1.9759 & 0.9987 & NS \\
\hline & & 6 & 1.6849 & 0.9990 & NS \\
\hline & & 15 & 1.6196 & 0.9992 & NS \\
\hline \multirow[t]{2}{*}{3} & 53 & 10 & $6 \cdot 3332$ & 0.9782 & $<() \cdot()(0) 1$ \\
\hline & & 17 & 6.5075 & $(0.9793$ & $<0 \cdot()() 1$ \\
\hline \multirow[t]{2}{*}{4} & 59 & 6 & $2 \cdot 8983$ & 0.9982 & $<0 \cdot 1$ \\
\hline & & 24 & $3 \cdot 2608$ & 0.9978 & $<0 \cdot() 2$ \\
\hline \multirow[t]{3}{*}{5} & 59 & 9 & $2 \cdot 8601$ & 0.9978 & $<0 \cdot 1$ \\
\hline & & 15 & $6 \cdot 5432$ & 0.9940 & $<0 \cdot(x) 1$ \\
\hline & & 18 & $12 \cdot 8876$ & 0.9790 & $<0) \cdot(0) 1$ \\
\hline \multirow{2}{*}{6} & & 11 & $4 \cdot 0741$ & 0.9961 & $<() \cdot(0) 1$ \\
\hline & & 17 & $5 \cdot 5827$ & 0.9926 & $<0 \cdot(0) 1$ \\
\hline \multirow[t]{2}{*}{7} & 63 & 5 & $3 \cdot 7093$ & 0.9967 & $<0 \cdot(0) 1$ \\
\hline & & 9 & 5.9026 & 0.9938 & $<0 \cdot(0) 1$ \\
\hline \multirow[t]{4}{*}{8} & 68 & 2 & 1.9980 & 0.9985 & NS \\
\hline & & 7 & $2 \cdot 5982$ & 0.9978 & NS \\
\hline & & 11 & 3.9777 & 0.9995 & $<() \cdot(x) 1$ \\
\hline & & 18 & $6 \cdot 2882$ & 0.9930 & $<() \cdot(x) 1$ \\
\hline \multirow[t]{2}{*}{9} & 68 & 5 & $2 \cdot 1697$ & 0.9987 & NS \\
\hline & & 12 & $4 \cdot 2282$ & 0.9952 & $<0 \cdot(00) 1$ \\
\hline \multirow[t]{3}{*}{10} & 68 & 5 & $3 \cdot 0625$ & 0.9974 & $<0) \cdot(15$ \\
\hline & & 12 & $3 \cdot 5322$ & 0.9963 & $<() \cdot() 1$ \\
\hline & & 18 & $4 \cdot 0109$ & 0.9953 & $<0 \cdot(x) 1$ \\
\hline
\end{tabular}

joints of the hands and in this case we have shown the worst affected joint. The patients with RA chosen all had classical or definite disease by the criteria of the American Rheumatism Association. ${ }^{9}$ All patients with RA had active synovitis in the small joints of the hands when entered in the study and all but two received second or third line drug therapy during at least part of the period of study.

\section{Results}

The reproducibility and $95 \%$ confidence limits of serial image analysis measurements in the head of the proximal phalanx of the middle finger in pairs of control radiographs are shown in Table 1 . Using the normal ranges for mean and standard deviation of changes of polar signature subtraction thus defined, changes in serial RA films defined by image analysis were compared with changes in the Larsen index. Significant changes were found in 13 of 15 RA films by image analysis but in only nine sets of films by Larsen scoring (Table 2).

In the last part of the study we examined the rapidity with which radiological changes could be shown to develop in 21 further patients with RA, in whom the worse affected PIP or MCP joint w需 chosen. Significant changes occurred in 15 of the joints (Tables 3 and 4). Changes occurred as early four months, and in 11 of these joints change occurred in less than 12 months. In one case (patieg No 6 , female) radiological improvement suggestive of healing was seen.

\section{Discussion}

In this study we have investigated the potentia usefulness of image analyse software in the serias measurement of radiographic changes occurring ib periarticular bone in patients with RA and using hand radiographs which could be produced in any routine $x$ ray department. We have shown first that these measurements appear reproducible pairs of non-RA hand radiographs taken over period of six months. A six month time period was chosen arbitrarily as being long enough to includo any errors that might conceivably be due to repक sitioning, radiography, film processing, and image analysis but short enough to avoid major biologic changes in normal bone in most subjects. Secondle. using $95 \%$ confidence limits calculated in these 
control subjects, we then studied serial films in patients with RA and have shown changes in a single PIP joint over periods of three to 10 months. The image analysis technique appeared more sensitive than a standard visual grading. Lastly, in a study of the worst affected MCP or PIP joints in 21 further sets of RA films we found that changes appeared as early as four months from the baseline measurements. Although all but two of these patients were receiving second or 'third line' drug therapy during part of the period of study, clinical features of disease activity had been at least partially controlled in 15 and they are likely to be reasonably representative of RA patients with active synovitis in small joints of the hands seen in most hospital outpatient clinics. Thus in this study we have shown that in principle image analysis techniques may be used as an objective, reproducible and relatively sensitive measure of the changes occurring in periarticular bone of standard hand radiographs in RA. We suggest that it would now be worth applying this technique to future large scale studies of putative disease modifying drugs in RA. The present image analysis software is relatively slow (hence the restriction in this study of serial measurements to individual joints) and requires further development to allow rapid measurement in multiple joints. Although the present study was directed at measurements of the bone loss occurring in RA, there seems no reason why similar techniques could not be applied to measurements of the new bone formation (osteophytosis) occurring in osteoarthritis.

We are grateful to the Arthritis and Rheumatism Council for financial support.

\section{References}

1 Sharp J T, Lidsky M D, Collins L C, Moreland J C. Methods of scoring the progression of radiological change in rheumatoid arthritis. Arthritis Rheum 1971; 14: 706-20.

2 Larsen A, Dale K, Eek M. Radiographic evaluation of rheumatoid arthritis and related conditions by standard reference films. Acta Radiol [Diagn] (Stockh) 1922; 18: 481-91.

3 Maziere B, Kuntz D, Coma D, Rycheweart A. In vivo analysis of bone calcium by local neutron selivation of the hand: results in normal and osteoporotic subjects. J Nucl Radiat 1979; 10: 85-91.

4 Johnston C C, Smith D M, Yu P, Deiss W A. In vivo measurement of bone mass in the radius. Metabolism 1968; 17: 1140-53.

5 Buckland-Wright J C. $X$-ray assessment of activity in rheumatoid disease. $\mathrm{Br} J$ Rheumatol 1983; 22: 3-10.

6 Buckland-Wright J C, Carmichael I, Walker S R. Quantitative microfocal radiography accurately detects joint changes in rheumatoid arthritis. Ann Rheum Dis 1986; 45: 379-83.

7 Smith R A. Digital film-making. New York: Springer, 1983; 1: 28-45.

8 Browne M A. Gaydecki P A. High speed spline fitting with application to boundary tracing in low contrast digital images. Comput Biol Med (in press).

9 Ropes M W. Diagnostic criteria for rheumatoid arthritis (1959 revision). Ann Rheum Dis 1959; 18: 48-53. 